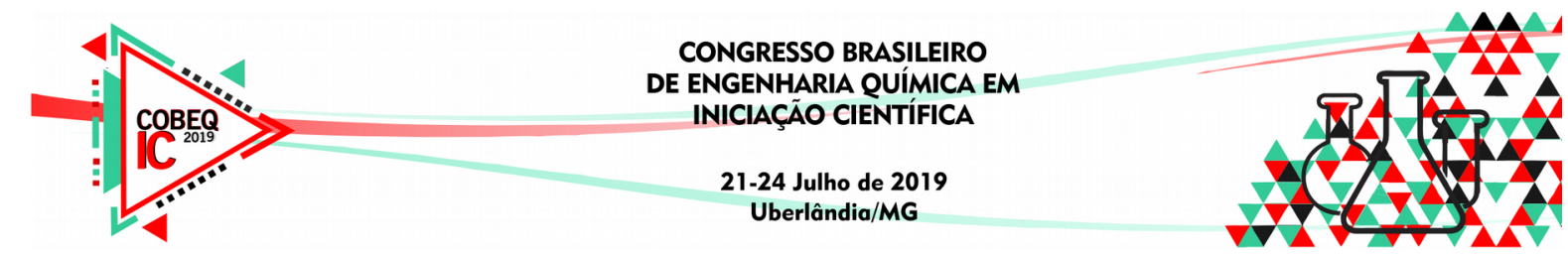

\title{
ANÁLISE DO POTENCIAL FERMENTATIVO DE LEVEDURAS ISOLADAS DE LATÍCINIO EM FONTES DE CARBONO ALTERNATIVAS
}

\author{
T. M. TANAKA ${ }^{1}$, J. M. HONMA ${ }^{2}$ e D. T. VARESCHINI ${ }^{1}$ e M. L. GIMENES ${ }^{1}$ \\ ${ }^{1}$ Universidade Estadual de Maringá, Departamento de Engenharia Química \\ ${ }^{2}$ Universidade Estadual de Maringá, Departamento de Engenharia de Alimentos \\ E-mail para contato: janainahonma@gmail.com
}

\begin{abstract}
RESUMO - A prospecção de novos microrganismos vem sendo uma das áreas de maior enfoque da biotecnologia, com o objetivo de utilizá-los em indústrias de alimento, na área da saúde e do meio ambiente. O objetivo do trabalho foi avaliar a capacidade de assimilação e fermentação de diferentes fontes de carbono, como frutose, maltose, amido solúvel e celobiose, por seis linhagens de microrganismos isolados de laticínio, através de cultivos independentes em Meio Mineral Suplementado (MMS). Os testes foram conduzidos a $30^{\circ} \mathrm{C}$ por um período de 264 $\mathrm{h}$, com intervalo de inspeção de $24 \mathrm{~h}$. Observou-se que após as primeiras $24 \mathrm{~h}$ de cultivo, os substratos foram assimilados pelas linhagens estudadas. A linhagem P1 apresentou fermentação vigorosa com todos os substratos. Além disso, para os substratos frutose, maltose e celobiose os resultados obtidos foram melhores quando comparados com o amido. Conclui-se que as linhagens estudadas são alternativas para serem empregadas em processos fermentativos nos quais os substratos testados estão biodisponíveis.
\end{abstract}

\section{INTRODUÇÃO}

Leveduras são microrganismos pertencentes ao reino fungi, podendo ser prospectadas partindo de diferentes substratos e habitats. Elas podem apresentar características específicas e diversidade metabólica, além de conseguirem assimilar diversos compostos orgânicos (Santos et al., 2012).

Diferente de quando se usa fungos filamentosos, ao utilizar leveduras em grande escala são obtidas algumas vantagens como a grande concentração de enzimas, curtos ciclos de fermentação, uso de meios de fermentação de baixo custo e baixa patogenicidade (Farias; Vital, 2008). Ademais, com o aumento da disponibilidade de substrato em resíduos industriais, novas pesquisas vêm sendo realizadas com o objetivo de converter esses substratos em produtos de valor agregado.

A indústria alimentícia tem mostrado importante papel na economia do país, dando destaque ao setor de laticínios, que se encontra entre os quatro principais setores da indústria de alimentos, perdendo apenas para derivados de carne, setor de beneficiamento de café, chá e cereais e o setor açucareiro (Carvalho, 2010). 


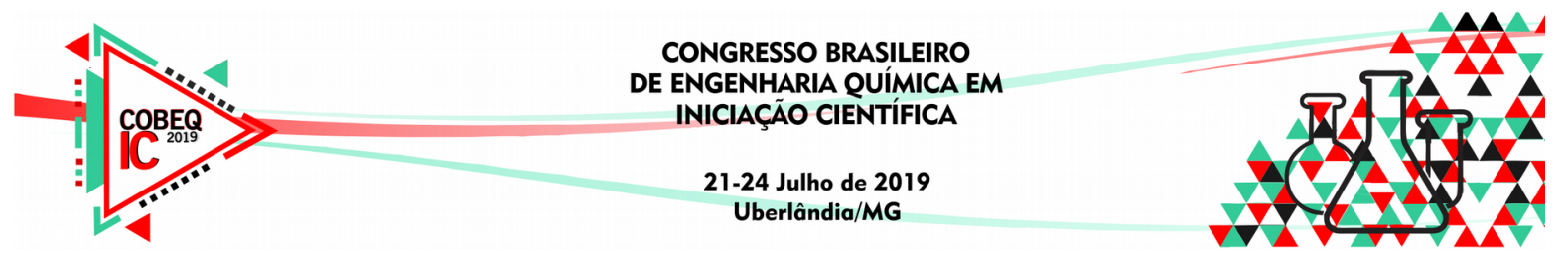

A bioprospecção é uma das atividades mais antigas do homem, sendo definida em 1993 como "a exploração da biodiversidade para a descoberta de recursos genéticos e substâncias bioquímicas comercialmente úteis" (Laird, S. A., 2002), porém essa definição é incompleta. Hoje, esse termo também é muito utilizado para descrever a coleta e triagem de novos seres vivos para fins comerciais, tanto na área da saúde, quanto na de alimentação e de problemas ambientais (Artuso, 2002). Sabe-se que existe mais de 700 espécies de leveduras prospectadas, obtidas tanto no meio ambiente, quanto em animais e seres humanos (Santos et al., 2012).

O objetivo do trabalho foi avaliar a capacidade de assimilação e fermentação de frutose, maltose, amido solúvel e celobiose por diferentes microrganismos isolados de laticínio, através de cultivos em meio mineral suplementado.

\section{MATERIAL E MÉTODOS}

Seis linhagens isoladas em trabalhos prévios (Honma, 2018) de um laticínio localizado na cidade de Guaraçaí, São Paulo, Brasil, foram mantidas em meio YEPL sólido (em g.L - $^{-1}$ : extrato de levedura, 20,0; peptona bacteriológica, 20,0; ágar-ágar, 15,0; lactose, 20,0) a $4{ }^{\circ} \mathrm{C}$. Para denominar essas linhagens foram utilizados os códigos P1, PI1, PI3 (isolados do queijo parmesão), 1TE (primeiro tanque de efluente), SR (soro residual da produção de queijo ricota) e STFB (tanque de soro destinado a produtores rurais).

Para testar se estas seis linhagens bioprospectados de um ambiente industrial conseguiam assimilar e fermentar, em cultivos independentes, substratos como frutose, maltose, amido solúvel e celobiose como fontes únicas de carbono, conduziu-se os experimentos em tubos de ensaio contendo $10 \mathrm{~mL}$ de Meio Mineral Suplementado - MMS composição (g.L $\left.\mathrm{L}^{-1}\right)$ : $\left(\mathrm{NH}_{4}\right)_{2} \mathrm{SO}_{4}, 5,0 ; \mathrm{KH}_{2} \mathrm{PO}_{4}, 3,0 ; \mathrm{MgSO}_{4} .7 \mathrm{H} 2 \mathrm{O}, 0.5$ (Verduyn et al., 1992); extrato de levedura, 4,5; peptona bacteriológica, 7,5; substrato, 20,0. O pH foi ajustado para 6,0 usando $\mathrm{NaOH}$. Em seguida, adicionou-se um tubo de Durham invertido em cada um dos tubos com a solução e esterilizou-os em autoclave $\left(121^{\circ} \mathrm{C}, 15 \mathrm{~min}\right.$.). Não foi adicionados solução de vitaminas e elementos traço, porém colocou-se uma solução indicadora de azul de bromotimol $\left(0,6\right.$ g. $\left.\mathrm{L}^{-1}\right)$ esterilizada por filtração $(0,45 \mu \mathrm{m})$. De acordo com Kutzman et al. (2011), quando os açúcares são consumidos, o MMS contendo a solução indicadora reage alterando a cor do meio de verde para amarelo. Mas, se os açúcares não forem consumidos e os aminoácidos presentes forem utilizados como fonte de carbono, o meio torna-se azul.

Antes de realizar o inóculo das linhagens estudadas nos tubos contendo MMS, as mesmas foram expandidas sem meio YEPL (g.L - $^{-1}$ : extrato de levedura, 20,0; peptona bacteriológica, 20,0; substrato, 20,0). Os microrganismos foram inoculados na concentração de 1:10. Um tubo de ensaio sem substrato foi usado como controle negativo (Honma et al., 2018). Os tubos foram incubados a $30^{\circ} \mathrm{C}$ durante 11 dias (264h) e analisados em intervalos de $24 \mathrm{~h}$.

No teste de assimilação (indicado por " $A$ " nas tabelas 1, 2 e 3), foram consideradas positivas as amostras que o meio se tornou turvo após ser incubado. Já para fermentação (indicado por $\mathrm{F}$ nas tabelas), considerou-se positivos aqueles que tiveram o tubo de Durham preenchido com gás. Os resultados foram expressos da seguinte maneira: - (negativo, não 


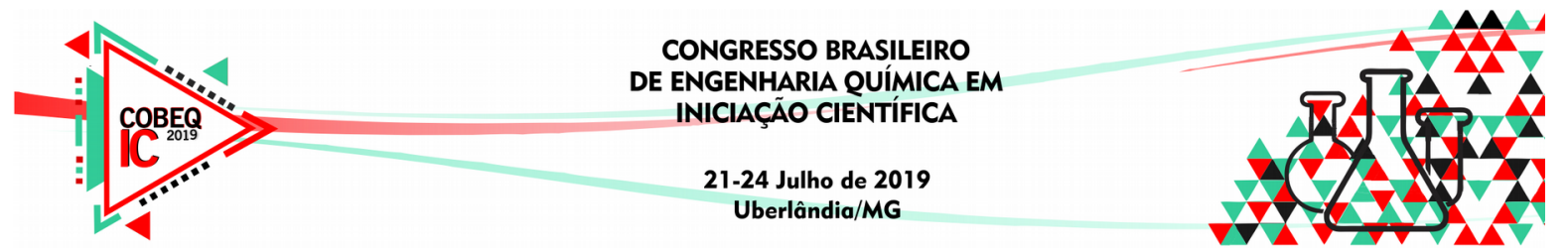

assimilou ou não fermentou); $+^{\mathrm{o}}$ (tubo de Durham preenchido com uma pequena bolha de gás); $+{ }^{1 / 3}$ (1/3 do tubo de Durham preenchido com gás) $;+{ }^{1 / 2}$ (metade do tubo de Durham preenchido com gás); + (positivo, com tubo de Durham totalmente, ou mais da metade, preenchido com gás).

\section{RESULTADOS E DISCUSSÃO}

Em termos da capacidade das seis linhagens (P1, PI1, PI3, 1TE, SR e STFB) em fermentar mono- (frutose) e dissacarídeos (maltose, celobiose), observou-se que a maioria das linhagens avaliadas apresentaram início de fermentação (tubo de Durham preenchido com uma pequena bolha de gás) nas primeiras $24 \mathrm{~h}$ do teste, exceto a linhagem STFB que nesse intervalo de tempo ainda não havia começado a fermentar com celobiose. Ainda em relação à fermentação, notou-se que após $24 \mathrm{~h}$ de cultivo com amido não foi observado produção de gás por nenhuma das linhagens.

Tabela 1 - Resultado do teste de assimilação e fermentação em MMS das seis linhagens de leveduras, após $24 \mathrm{~h}$ de cultivo

\begin{tabular}{|c|c|c|c|c|c|c|c|c|}
\hline \multirow{3}{*}{ Linhagens } & \multicolumn{8}{|c|}{ Após $24 \mathrm{~h}$} \\
\hline & \multicolumn{2}{|c|}{ Frutose } & \multicolumn{2}{|c|}{ Maltose } & \multicolumn{2}{|c|}{ Amido } & \multicolumn{2}{|c|}{ Celobiose } \\
\hline & $\mathrm{A}$ & $F$ & $\bar{A}$ & $\mathrm{~F}$ & $\bar{A}$ & $\mathrm{~F}$ & $\mathrm{~A}$ & $\mathrm{~F}$ \\
\hline $\mathrm{P} 1$ & + & $+^{\circ}$ & + & $+^{\circ}$ & + & - & + & $+^{o}$ \\
\hline PI1 & + & $+^{o}$ & + & $+^{o}$ & + & - & + & $+^{o}$ \\
\hline PI3 & + & $+^{\circ}$ & + & $+^{o}$ & $+^{*}$ & - & + & $+^{o}$ \\
\hline $1 \mathrm{TE}$ & + & $+^{o}$ & + & $+^{o}$ & + & - & + & $+^{o}$ \\
\hline SR & + & $+^{o}$ & + & $+^{o}$ & $+^{*}$ & - & + & - \\
\hline STFB & + & $+^{0}$ & + & $+^{o}$ & + & - & + & - \\
\hline
\end{tabular}

Onde, A: assimilação; F: fermentação; - : negativo, não assimilou ou fermentou; $+^{\circ}:$ tubo de Durham preenchido com uma pequena bolha de gás; $++^{1 / 3}: 1 / 3$ do tubo de Durham preenchido com gás; $++^{1 / 2}:$ metade do tubo de Durham preenchido com gás; $+:$ tubo de Durham totalmente (ou mais de $1 / 2$ ) preenchido com gás; $+^{*}$ : traços de cor azul no meio.

A partir da análise dos dados de cultivo apresentados na Tabela 1 notou-se que nas primeiras 24 horas de cultivo houve a assimilação de todos os substratos por todas as linhagens.

$\mathrm{Na}$ análise de $168 \mathrm{~h}$ de cultivo, as leveduras apresentaram melhoras significativas em relação à fermentação, como por exemplo, a P1 e PI3, que alcançaram uma fermentação vigorosa com frutose e celobiose, preenchendo por completo os tubos de Durham. Além disso, nesse tempo, houve o início da fermentação em amido e o aumento da bolha de gás em todos os cultivos. 


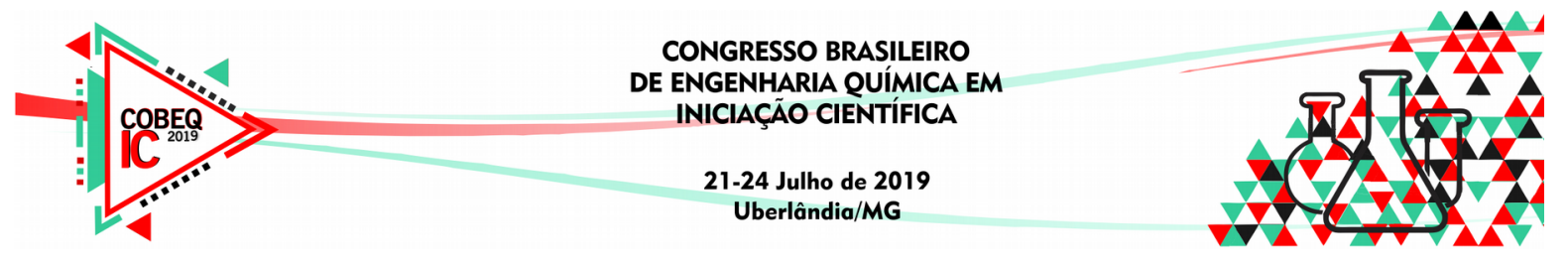

Tabela 2- Resultado do teste de assimilação e fermentação em MMS das seis linhagens de leveduras após $168 \mathrm{~h}$ de cultivo

\begin{tabular}{|c|c|c|c|c|c|c|c|c|}
\hline \multirow{3}{*}{ Linhagens } & \multicolumn{8}{|c|}{ Após $168 \mathrm{~h}$} \\
\hline & \multicolumn{2}{|c|}{ Frutose } & \multicolumn{2}{|c|}{ Maltose } & \multicolumn{2}{|c|}{ Amido } & \multicolumn{2}{|c|}{ Celobiose } \\
\hline & $\mathrm{A}$ & $\mathrm{F}$ & $\mathrm{A}$ & $\mathrm{F}$ & $\mathrm{A}$ & $\mathrm{F}$ & A & $\mathrm{F}$ \\
\hline $\mathrm{P} 1$ & + & + & + & $++^{1 / 2}$ & + & $+^{\circ}$ & + & + \\
\hline PI1 & + & $++^{1 / 2}$ & + & $+{ }^{1 / 3}$ & + & $+^{\mathrm{o}}$ & + & $++^{1 / 2}$ \\
\hline PI3 & + & + & + & $++^{1 / 3}$ & + & $+^{\mathrm{o}}$ & + & + \\
\hline $1 \mathrm{TE}$ & + & $++^{1 / 3}$ & + & $++^{1 / 2}$ & + & $+^{\mathrm{o}}$ & + & + \\
\hline SR & + & + & + & $+^{o}$ & $+^{*}$ & $+^{o}$ & + & $++^{1 / 3}$ \\
\hline STFB & + & $+^{1 / 3}$ & + & $++^{1 / 2}$ & + & $+^{\mathrm{o}}$ & + & $+^{1 / 2}$ \\
\hline
\end{tabular}

Onde, A: assimilação; F: fermentação; - : negativo, não assimilou ou fermentou; ${ }^{{ }^{\circ}}$ : tubo de Durham preenchido com uma pequena bolha de gás; $+{ }^{1 / 3}: 1 / 3$ do tubo de Durham preenchido com gás; $+{ }^{1 / 2}:$ metade do tubo de Durham preenchido com gás; + : tubo de Durham totalmente (ou mais de $1 / 2$ ) preenchido com gás; $+{ }^{*}$ : traços de cor azul no meio.

Ao analisar as amostras no tempo final estabelecido para os cultivos, ou seja, após onze dias (264 h), encontraram-se os resultados apresentados na Tabela 3.

Tabela 3-Resultado do teste de assimilação e fermentação das seis linhagens isoladas, após 264 h de cultivo

\begin{tabular}{|c|c|c|c|c|c|c|c|c|}
\hline \multirow{3}{*}{ Linhagens } & \multicolumn{8}{|c|}{ Após $264 \mathrm{~h}$} \\
\hline & \multicolumn{2}{|c|}{ Frutose } & \multicolumn{2}{|c|}{ Maltose } & \multicolumn{2}{|c|}{ Amido } & \multicolumn{2}{|c|}{ Celobiose } \\
\hline & $\mathrm{A}$ & $\mathrm{F}$ & $\mathrm{A}$ & $\mathrm{F}$ & A & $\mathrm{F}$ & $\mathrm{A}$ & $\mathrm{F}$ \\
\hline $\mathrm{P} 1$ & + & + & + & $+^{1 / 2}$ & + & $+^{\circ}$ & + & + \\
\hline PI1 & + & $+^{1 / 2}$ & + & $+^{1 / 3}$ & + & $+^{o}$ & + & $++^{1 / 2}$ \\
\hline PI3 & + & + & + & $++^{1 / 3}$ & + & $+^{o}$ & + & + \\
\hline $1 \mathrm{TE}$ & + & $++^{1 / 2}$ & + & $++^{1 / 2}$ & + & $+^{o}$ & + & + \\
\hline SR & + & + & + & $++^{1 / 3}$ & $+{ }^{*}$ & $+^{o}$ & + & $++^{1 / 3}$ \\
\hline STFB & + & $++^{1 / 2}$ & + & $++^{1 / 2}$ & + & $+^{o}$ & + & $++^{1 / 2}$ \\
\hline
\end{tabular}

Onde, A: assimilação; F: fermentação; - : negativo, não assimilou ou fermentou; $+^{\circ}$ : tubo de Durham preenchido com uma pequena bolha de gás; $+^{1 / 3}: 1 / 3$ do tubo de Durham preenchido com gás; $+^{1 / 2}:$ metade do tubo de Durham preenchido com gás; + : tubo de Durham totalmente (ou mais de $1 / 2$ ) preenchido com gás; $+{ }^{*}$ : traços de cor azul no meio.

No final do teste, foi possível observar que para os substratos frutose, maltose e celobiose os resultados obtidos foram melhores quando comparados com o amido. As seis linhagens conseguiram assimilar o amido nas primeiras 24 horas, porém, quanto à fermentação, mesmo após as 264 horas, nenhuma apresentou resultados vigorosos, uma vez que estavam apenas com uma pequena bolha, ou seja, havia apenas iniciado o processo de fermentação. Ainda sobre o amido, observou-se que as linhagens PI3 e SR apresentaram um halo azulado sobre a superfície do MMS, como apresentado na Figura 1. Essa coloração sugere que os microrganismos cresceram utilizando inicialmente aminoácidos presente no meio para depois utilizar o substrato principal. (Kutzmanet al., 2011).

Figura 1 - Linhagens cultivadas em MMS com amido solúvel, após 24 h de incubação.

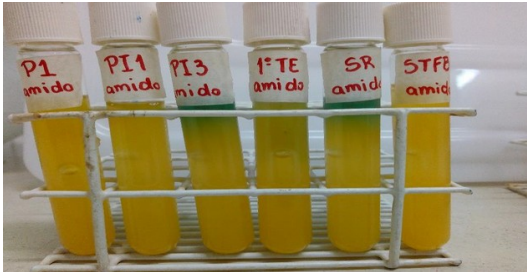




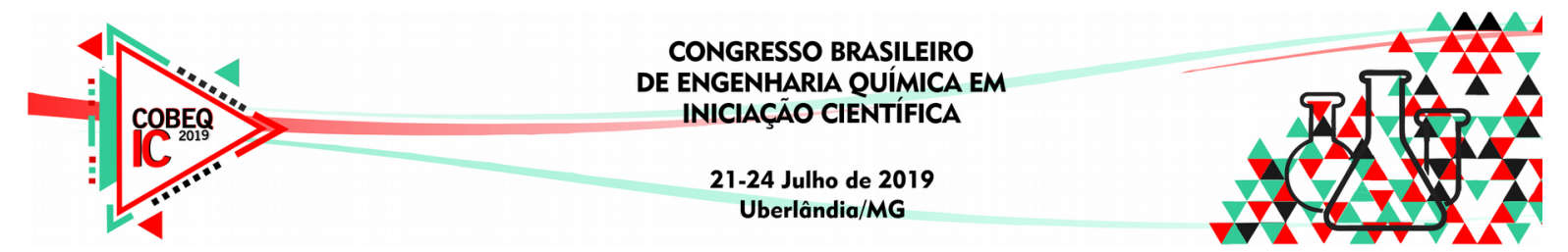

O amido é presente em inúmeras matérias-primas agrícolas e é reportado como um substrato conveniente para produção de etanol (Bastos et al., 2015; Castro et al., 2011), mas embora muitos açúcares possam ser fermentados e assimilados pelas leveduras, a capacidade para degradar amido não é uma característica comum entre elas. Nesse sentido, Bastos et al. (2015) apontaram que as leveduras capazes de degradar o amido têm sido consideradas microrganismos promissores.

É conhecido que as enzimas glicosidases ( $\beta$-glicosidases) convertem moléculas de celobiose em duas moléculas de glicose (Corazza et al., 2005; Zhang et al., 2006; Zhang e LYND, 2004). Logo, leveduras que possuam enzimas capazes de hidrolisar celobiose são promissoras para aplicações na fermentação de materiais lignocelulósicos, eliminando a etapa de hidrólise prévia à fermentação, pois o microrganismo mais frequentemente utilizado para a fermentação de etanol em processos industriais é a Saccharomycescerevisiae, que fermenta materiais lignocelulósicos desde que estes sejam previamente hidrolisados.

Em referência aos processos fermentativos de maltose por leveduras, estes têm sido objeto de muitas pesquisas. Pois, pelo fato da maltose possuir uma taxa de fermentação abaixo da glicose, existem esforços para melhorar essa eficiência, sendo o transporte da maltose para o interior das células o principal fator de controle sobre a taxa de fermentação (Ganatsios et al., 2014). As linhagens de leveduras avaliadas no presente trabalho mostraramse capazes de fermentar maltose, mas também em taxas menores quando comparado à glicose.

\section{CONCLUSÕES}

Conclui-se que, as seis linhagens cultivadas em Meio Mineral Suplementado, mostraram-se aptas a assimilarem os substratos amido, maltose, frutose e celobiose no período de 24 horas. Durante esse período também houve o início da fermentação para os substratos testados, com exceção do amido. Além disso, foi observado um halo azul sobre a superfície do MMS com amido e as linhagens PI3 e SR, indicando que os microrganismos cresceram utilizando inicialmente aminoácidos presentes no meio para depois utilizar o substrato principal. No final da análise, 264 horas, notou-se uma melhora significativa com relação à fermentação, dando destaque as linhagens P1 e PI3. Nesse sentido, conclui-se que as linhagens estudadas possuem potencial para utilização em processos de fermentação de resíduos de origem agroindustrial que contenham em sua composição os substratos testados, demonstrando assim o potencial da prospecção de novas linhagens em ambientes industriais.

\section{REFERÊNCIAS}

ARTUSO, A. Bioporspecting, benefi sharing, and biotechnological capacity building. Word Development, v.30, n.8, p. 1355-1368, ago. 2002.

BASTOS, C. M. S.; COSTA, S. T. C.; ABREU-LIMA, T. L.; ZUNIGA, A. D. G.; CARREIRO, S. C. Efeito das condições de cultivo na produção de amilase por duas linhagens de leveduras. Revista Brasileira de Biociências., Porto Alegre, v. 13, n. 3, p. 123-129, 2015.

CARVALHO, G. R. O retrato do mercado nacional. Revista Leite \& Derivados, v. 19, n. 118, p. 22-28, 2010. 


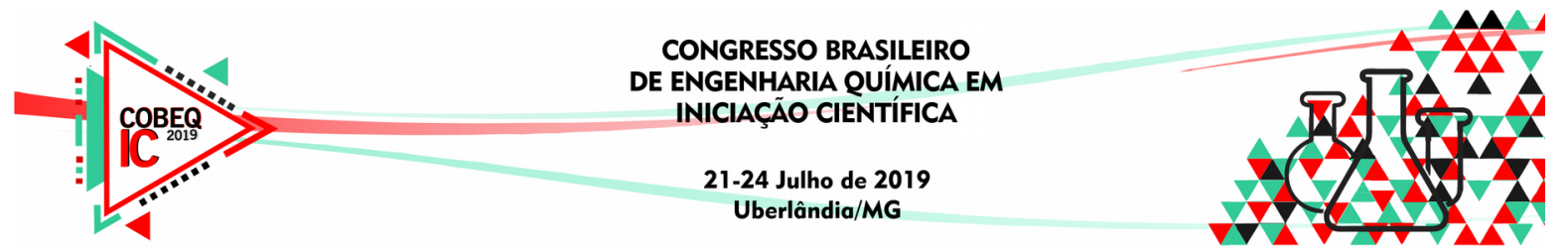

CASTRO, A. M.; ANDRÉA, T. V.; CARVALHO, D. F.; TEIXEIRA, M. M. P.; CASTILHO, L. R.; FREIRE, D. M. G. Valorization of residual agroindustrial cakes by fungalproduction of multienzyme complexes and their use in cold hydrolysis of raw starch. Waste Biomass Valor., v. 2, p. 291-302, 2011.

CORAZZA, F. C.; CALSAVARA, L. P. V.; MORAES, F. F.; ZANIN, G. M.; NEITZEL, I. Determination of inhibition in the enzymatic hydrolysis of cellobiose using hybrid neural modeling. BrazilianJournalofChemicalEngineering., v. 22, n. 1, p. 19-29, 2005.

FARIAS, M. V. D.; VITAL, M. J. S. Produção de enzimas hidrolíticas por leveduras isoladas de solos de áreas preservadas em roraima, Brasil. Universidade Federal de Roraima UFR, 2008.

GANATSIOS, V.; KOUTINAS, A. A.; BEKATOROU, A.; KANELLAKI, M.; NIGAM, P. Promotion of maltose fermentation at extremely low temperatures using a cryotolerantSaccharomyces cerevisiae strain immobilized on porous cellulosic material. Enzyme and Microbial Technology., v. 66, p. 56-59, 2014.

HONMA, J. M.; TANAKA, T. M.; VARESCHINI, D. T.; GIMENES, M. L. Influence of the mineral medium supplementation in biochemical assimilation and fermentation test.Galoá Proceedings., v. 1, 2018.

KURTZMAN, C. P.; FELL, J. W.; BOEKHOUT, T.; ROBERT, V. Methods for isolation, phenotypic characterization and maintenance of yeasts. In: KURTZMAN, C. P.; FELL, J. W.; BOEKHOUT, T. The Yeasts, a Taxonomic Study. Elsevier Science: 5th edition, 2011.

LAIRD, S. A. Biodiversity and traditional knowledge - equitable partnerships in practice, Edited By Sarah A. Laird, Earthscan Publications Ltd., London \& Sterling (USA), p. xxii. 2002.

SANTOS, T. T.Identificação e análise do potencial enzimático de leveduras isoladas do afloramento rochoso do morro da pioneira - Bahia.2012, 54f. Trabalho de conclusão de curso (Bacharelado em Biologia) Universidade Federal do Recôncavo da Bahia. Cruz das almas, 2012.

VERDUYN, C.; POSTMA, E.; SCHEFFERS, W. A.; VANDIJKEN, J. P. Effect of benzoic acid on metabolic fluxes in yeasts: a continuous-culture study on the regulation of respiration and alcoholic fermentation. Yeast., v. 8, p. 501-517, 1992.

ZHANG, Y-H. P.; HIMMEL, M. E.; MIELENZ, J. R. Outlook for cellulase improvement: Screening and selection strategies. Biotechnology Advances., n. 24, p. 452-481, 2006.

ZHANG, Y-H. P.; LYND, L. R. Toward an aggregated understanding of enzymatic hydrolysis of cellulose: noncomplexed cellulose systems. Biotechnology and Bioengineering., $\mathrm{v}$. 88, p. 797-824, 2004. 